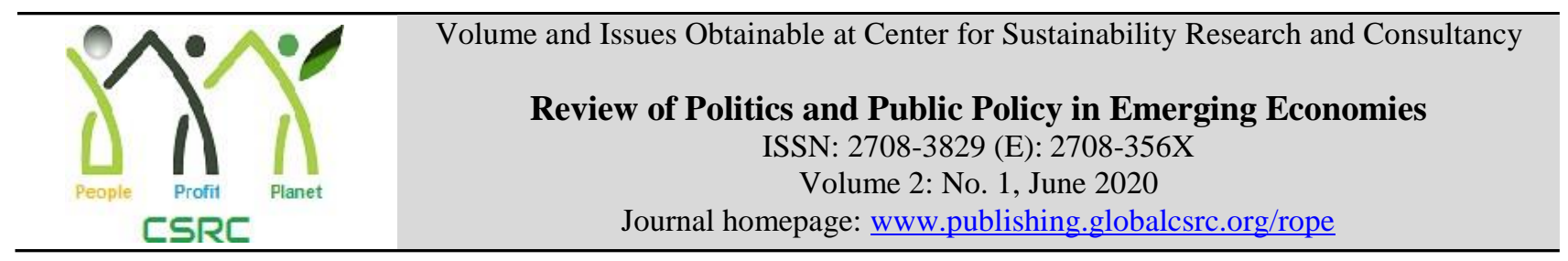

\title{
Empirical Analysis of Local Residents' Support in a Selected Special Event
}

\author{
${ }^{1}$ Hassnah Wee, ${ }^{2}$ Alfian Thomas \\ ${ }^{1}$ Universiti Teknologi MARA (UiTM), Malaysia \\ ${ }^{2}$ Politeknik Tawau Sabah, Malaysia, alfian.thomas@gmail.com
}

\begin{tabular}{l}
\hline ARTICLE DETAILS \\
\hline History \\
Revised format: May 2020 \\
Available Online: June 2020 \\
\\
\hline Keywords \\
Local Residents Support, \\
Community Participations, \\
Local Hospitality, Event \\
Sustainability \\
\hline
\end{tabular}

JEL Classification

$M 0, M 1$

\section{OPEN ACCESS}

\begin{abstract}
The support and involvement in an event by local citizens will indirectly affect the performance of event activities, and local communities would be influenced in their behavior towards cooperation in planning and holding the function. This study intend to investigate the level of residents' support and local community participation towards the Putrajaya Flower and Garden Festival, Putrajaya (FLORIA Putrajaya). Besides, this study attempts to determine the relationship between local hospitality towards the event sustainability. Sample population for this study included the visitors who visited Putrajaya, Malaysia. The results were significant between overall variables (local residents support; local community participations; local hospitality) of local residents' support toward event sustainability and destination image $(\beta=.120, \mathrm{p}<0.01)$. The findings of this study can be used by event organisers, particularly in Putrajaya, in reviewing the current movements of participation by local residents or host-community towards the event operations. In addition, the outcome of this study may increase the awareness of event organisers regarding the importance of getting support from the local residents towards event sustainability and host-destination image.
\end{abstract}

(C) 2020 The authors, under a Creative Commons AttributionNonCommercial 4.0

Corresponding author's email address: alfian.thomas@gmail.com

Recommended citation: Wee, H., \& Thomas, A. (2020). Empirical Analysis of Local Residents' Support in a Selected Special Event. Review of Politics and Public Policy in Emerging Economies, 2 (1), 27-34

\section{Introduction}

The organisation of a special event such as carnivals has been recognized as an important and strategic initiative to increase tourism over the long term besides its advantages in terms of economic and noneconomic benefits. It can also improve the image of a destination and indirectly create sustainability by location branding (Jago, Dwyer, Lipman, Lill \& Vorster, 2010). Currently, demands and supplies have dropped for conventional sectors such as rural fishing, crafting and indigenous tribes, and other local populations have to seek new methods of improving their self-developed skills and information tools (Teh \& Cababan, 2007; Lepp, 2007; Wang, Yang, Chen, Yang \& Li, 2011). Besides, community tourism contributes for rural industrial development by providing local residents the skills and knowledge they required (Bramwell \& Lane, 1993; Mehmetoglu, 2001), host destination support (Mehmetoglu \& Ellingsen, 2005; Boo \& Busser, 2006), as well as indirectly offer tourist with high 
quality experience and increased awareness on environmental sustainability (Lepp, 2007: Lee, 2011). Therefore, in many situations the event is usually a driver for people to enter a specific place in the expectation that during their journey, they can partake in certain events and encounters.

Moreover, there is a need to establish sustainable tourism to meet the needs and requests to improve the community ability and expertise (Puczko \& Ratz, 2000). However, creating sustainable tourism will be challenging without the support from the neighbourhood (Fallon \& Kriwoken, 2003; Gursoy \& Rutherford, 2004; Nicholas, Thapa \& Ko, 2009). The support from local communities is also one of the key aspects in a sustainable community growth. This study was aimed at filling these gaps by concentrating on local citizen support, local community engagement and the local hospitality to explore the connection between citizen support and event sustainability.

\section{Literature Review}

The cooperation of local citizens especially in specific volunteer efforts is important in special events like the Putrajaya Flower and the Gardens Festival, which last for seven days. The relative focus on services that, for tourist measures, be quite geographical in terms of the physical environment not just because of various environments and geographies, but also because of the psychological environment like specific characteristics of tourists. Sustainable development has also been frequently debated within tourism sector as it is intended to satisfy the needs of travellers, create resources to fuel economic growth, preserve natural resources, increase citizens' quality of life and enhance potential prospects through the co-existence of tourist development and environmental sustainability (Eagles, McCool \& Haynes, 2002). Sebele (2010) also acknowledged that the tourism sector in a community has been a significant instrument for sustainability. This definition has been used in several countries for researching the impact of specific events on local destinations (Roche 1992).

Sustainability theories and practices were used to evaluate the involvement of local community or residents on sustainability of event and the host destination. Capra (2002) stated that the deeper understanding on human behaviour and ordinary systems allow event organizers to improve organizing a strategy and solution in addressing issues of un-sustainability. On the basis of the Putrajaya annual report in 2013, FLORIA Putrajaya acts to aid the government's aspiration of making Putrajaya a town in a garden and a revolutionary green town in all areas of design, management and growth. A research has been carried out by Berkes and Folke (1998) that established an internal disciplinary framework to observe the practice of environmental management by relating a social and ecological system, which produced illogical and non-natural result. In the theory of social exchange, the local community or residents intend to support and participate in events. They would gain information and knowledge to improve tourism when communicating with visitors. Thus, the host residents perceive that such exchanges are likely to benefit them without incurring unbearable costs.

Community involvement can be regarded either as a participant or a volunteer. Most events include a wide number of volunteers who will regularly monitor and communicate with various demographic ranges during an event of varying levels of volunteers. A voluntary organisation may also work concurrently in different parts of the site at the same time. Such so-called monitors will therefore be educated in a detailed training prior to going into the social environment, including addressing the issues and goals expected for the event. Volunteers are deemed a force base to sustain the event in the context of the Putrajaya Flower and Garden Festival. They are a critical part of what makes an experience year after year such a success. It is evident that events will not continue for long without the contributions of the volunteers. The position of the volunteer constitutes one of the most important pieces for the activities, including the functions of:

- Supporting the festival to reach potential targets

- Encouraging sustainability practices 
- Serving as a media mouthpiece

- Marketing public education

- Considering the trivialities of daily case activities in the event

- Getting good reviews

- Bridging the communication between outsiders and insiders

Volunteers from the festivals who engage regularly in various social networks in their neighbourhoods consider that it is their duty to make a difference to celebrations and gatherings despite minimal time and resources. In addition to ethically managing an event from organisations, the event attenders must also consider their economic, host groups and each other's obligations. Throughout the event sector, the idea regarding environmental sustainability growth may also be encouraged and disseminated (Yulan, 2013). Throughout the execution of the event, event managers must insure that the required information and signage are appropriately planned and located regardless of the equipment or mitigation measures. Officials, donors and guests must be told regarding these programs, their positions and the planned contributions. In other ways, the managers must also start discussing the different activities relevant to environmental sustainability during the event. By this manner, all viewers including foreign tourists can grasp the various initiatives, besides acknowledging and welcoming them. This is important as a maximum public support including the use of public transport system available (Laing \& Frost, 2010).

Residents may often have more favourable opinions on tourism if they consider that tourism trade provides individual benefits, but vice versa if they believe that these benefits are outweighed by costs (Teh \& Cabanban, 2007). In other terms, demonstrated enthusiasm for tourism is seen as a trade willingness. Host groups that are looking to draw on events to produce advantageous outcomes also need to consider and exploit interaction dynamics that promote cooperation. In many earlier studies (Solberg, 2003; Haxton, 2000; Barron \& Rihova, 2011), essential improvements to destination management by group engagement in special events have also been identified. Based on industry experts, several important factors have been identified to host special events, which can directly affect the image of a destination including the level of support from the community. This research seeks to determine tourist views. Therefore, the following hypothesis was developed as below:

H1 : There is a significant relationship between local community support and host-destination image.

\section{Methodology}

On the basis of the previous studies directed mainly by Jago, Dwyer, Lipman, van Lill, and Vorster (2010), it was agreed that concentration is given on the tourist-based interpretation regarding the relationships between the FLORIA Putrajaya and the image of location. Then, the local community support was evaluated as one of the latent components. In four major areas of Putrajaya Malaysia, which included Masjid Besi Putrajaya, Dataran Putra, Alamanda Shopping Mall and even IOI City Center, a sample of 300 participants was selected through convenience sampling. In March 2015, a self-completed questionnaire was created for the gathering of the necessary details for the analysis within a period of two weeks. For each question in each segment of the questionnaire, an equivalent 7-point Likert scale was utilised to help respondents to talk freely without prejudice besides being more accurate than the 5point Likert scale. Therefore, the Likert scale of 7 points is more desirable, as the respondents were pleased to display their stand on a scale of more points (Sekaran \& Bougie, 2009). The questions included in this research were founded on previous studies and adjusted (Jago et al., 2010). A pilot study was done on 30 respondents in the Shah Alam areas who were visitors. Cronbach's alpha was set under a reasonable range $(>.7)$ for each series of questions. Descriptive statistics was used to calculate the internal consistency specified by the mean and evaluate the relationship between the variables by the standard deviation for each element and inferential statistics. 


\section{Result and Discussion}

In general, Table 1 shows the demographic information of the respondents, which exhibited more than half of the respondents who were female with $54.0 \%(\mathrm{n}=162)$ compared to $46.0 \%(\mathrm{n}=138)$ male from the total respondents. These results anticipate that more female are visiting the FLORIA Putrajaya compared to male. Based on the table, most of the visitors were between 29 to 39 years old by $51.0 \%$ (n $=153)$, followed by $28.7 \%(\mathrm{n}=86)$ visitors who were in the age of 18 to 28 years old. Furthermore, $12.0 \%(\mathrm{n}=36)$ of the total visitors were in the age ranging from 40 to 49 years old and $5.3 \%(\mathrm{n}=16)$ of the visitors were between 50 to 59 years old. $2.3 \%(\mathrm{n}=7)$ visitors were in the age below than 18 years old and only $0.7 \%(n=2)$ of them were 60 years old. These results indicate that visitors who visit FLORIA Putrajaya are mostly young adults. In terms of level of education, $80 \%(\mathrm{n}=241)$ of the visitors had a university education (graduates); 17.0\% $(\mathrm{n}=51)$ of the respondents had a high school education and only $2.7 \%(\mathrm{n}=8)$ of the respondents had secondary school education. These results indicate that the education level of visitors who visit FLORIA Putrajaya is quite high. With regard to respondents' monthly income, the largest group with monthly income of RM 1000 - RM 3000 was 54.7\% ( $n=170)$, followed by RM 3000 - RM 5000 with 32.7\% ( $\mathrm{n}=98)$ and 9.0\% ( $\mathrm{n}=27)$ with monthly income of less than RM 1000. Only $1.7 \%(n=5)$ of the respondents had monthly income of RM 5000 or above.

4.1 Demographic characteristics of the respondents $(n=300)$

Table 1: Frequency Distribution of Respondents

\begin{tabular}{|l|l|l|l|l|l|}
\hline \multicolumn{5}{|c|}{ Frequency Distribution - Respondent's } \\
\hline & & & Frequency & Percent & \\
\hline & Gender & Male & 138 & 46.0 & \\
\hline & & Female & 162 & 54.0 & \\
\hline & Age & $<18$ & 7 & 2.3 & \\
\hline & & $18-28$ & 86 & 28.7 & \\
\hline & & $29-39$ & 153 & 51.0 & \\
\hline & & $40-49$ & 36 & 12.0 & \\
\hline & & $50-59$ & 16 & 5.3 & \\
\hline & & $>60$ & 2 & .7 & \\
\hline & Education & Secondary School & 8 & 2.7 & \\
\hline & & High School & 51 & 17.0 & \\
\hline & & Graduate & 241 & 80.3 & \\
\hline & Occupation & Government Servant & 92 & 30.7 & \\
\hline & & Private Servant & 176 & 58.7 & \\
\hline & & Retired & 9 & 3.0 & \\
\hline & & Student & 23 & 7.7 & \\
\hline & Monthly Income & RM1000 & 27 & 9.0 & \\
\hline & & RM1000 - RM3000 & 170 & 56.7 & \\
\hline & & RM3000 - RM5000 & 98 & 32.7 & \\
\hline & & $>$ RM5000 & 5 & 1.7 & \\
\hline & Average length of visit & One Day & 137 & 45.7 & \\
\hline & & Two Days & 73 & 24.3 & \\
\hline & & Three Days and More & 90 & 30.0 & \\
\hline
\end{tabular}

4.2 Local Community Support

Table 2: Reported mean scores for Local Community Support towards FLORIA Putrajaya

\begin{tabular}{llcc}
\hline Indicators & $\begin{array}{l}\text { Variables } \\
\text { Local Community Support }\end{array}$ & $\begin{array}{c}\text { Mean } \\
\text { (M) }\end{array}$ & $\begin{array}{c}\text { Std. Deviation } \\
\text { (SD) }\end{array}$ \\
\hline CS 1 & Local residents are friendly. & 5.43 & 1.07 \\
CS 2 & I feel welcomed by local residents. & 5.56 & 0.91 \\
CS 3 & Local residents are willing to offer assistance. & 5.53 & 0.99 \\
CS 4 & Putrajaya tourism service quality is good. & 5.66 & 1.00
\end{tabular}




$\begin{array}{ll}\text { CS } 5 & \text { Local tourism service staff are friendly. } \\ \text { CS } 6 & \begin{array}{l}\text { Local tourism service staff are knowledgeable and have } \\ \text { proficient service skills. }\end{array} \\ \text { CS } 7 & \begin{array}{l}\text { I saw many volunteers working inside and outside of } \\ \text { festival area. }\end{array} \\ \text { CS 8 } & \text { Volunteers are knowledgeable. } \\ \text { CS 9 } & \text { Volunteers are good representatives of the festival and } \\ \text { CS 10 } & \begin{array}{l}\text { Putrajaya. } \\ \text { CS 11 }\end{array} \\ \text { CS } 12 & \begin{array}{l}\text { Putrajaya built sufficient directions / informational signs } \\ \text { for the festival. }\end{array} \\ & \begin{array}{l}\text { Public area has sufficient direction / } \\ \text { informational signs for the festival. }\end{array}\end{array}$

$\begin{array}{ll}5.64 & 1.01 \\ 5.53 & 1.12 \\ & \\ 5.51 & 1.16 \\ & \\ 5.36 & 1.26 \\ 5.42 & 1.21 \\ 5.52 & 1.17 \\ 5.50 & 1.14 \\ 5.52 & 1.15\end{array}$

Viewing at pattern shown in Table 2, most of the respondents agreed with all the statements given. As such, local residents were friendly $(M=5.43)$ with a standard deviation of $(S D=1.07)$. Meanwhile, the mean score for feeling welcomed by local community in Putrajaya was $(M=5.66)$ with a standard deviation of $(S D=0.91)$. In addition, respondents also agreed that local residents were willing to offer assistance where the mean was $(M=5.53)$ with a standard deviation of $(S D=0.99)$. Then, based on the result, respondents agreed that the quality of Putrajaya tourism was good to accommodate the visitors as the mean score was $(M=5.66)$ and standard deviation was $(S D=1.00)$. Furthermore, respondents agreed that service quality must come with friendly local tourism service staff with a mean score of $(M=5.64)$ and a standard deviation of $(S D=1.01)$. Local tourism service staff were also found to be knowledgeable and have proficient service skills showing a mean score of $(M=5.53)$ with a standard deviation of $(S D=1.12)$. Most of the respondents agreed that they saw many volunteers working inside and outside of festival area with a mean score of $(M=5.51)$ and a standard deviation of $(S D=1.16)$ and the level of knowledge for volunteer mean score was $(M=5.36)$ with a standard deviation of $(S D=1.26)$. Respondents also agreed that volunteers were good representatives of the festival and Putrajaya with a mean score $(M=5.42)$ and a standard deviation of $(S D=1.21)$. Road signs in Putrajaya were clear and easy to follow with a mean score $(M=5.52)$ and a standard deviation of $(S D=1.17)$. Most of respondents agreed that Putrajaya built sufficient direction signs for the festival with a mean score of $(M=5.50)$ and a standard deviation of $(S D=1.14)$. Signage for public area also came with sufficient directions and information by Putrajaya, which was agreed by respondents with a mean score of $(M=5.52)$ and standard deviation of $(S D=1.15)$. The entire mean score patterns indicate that respondents have a high support by the local community during the festival.

\subsection{Event Sustainability and Destination Image \\ Table 3: Reported mean scores for Event Sustainability and Destination Image}

\begin{tabular}{|c|c|c|c|}
\hline Indicators & $\begin{array}{l}\text { Variables } \\
\text { Event Sustainability and } \\
\text { Destination Image }\end{array}$ & $\begin{array}{l}\text { Mean } \\
(M)\end{array}$ & $\begin{array}{l}\text { Std. Deviation } \\
\text { (SD) }\end{array}$ \\
\hline ESDI 1 & $\begin{array}{l}\text { This festival effectively addressed a major theme } \\
\text { of Putrajaya a city-in-garden. }\end{array}$ & 5.86 & 0.92 \\
\hline ESDI 2 & The festival achieved its goal. & 5.85 & 1.01 \\
\hline ESDI 3 & $\begin{array}{l}\text { Putrajaya enhanced the visibility of Putrajaya } \\
\text { Flower \& Garden Festival in Malaysia. }\end{array}$ & 5.86 & 1.05 \\
\hline ESDI 4 & $\begin{array}{l}\text { Putrajaya has a capability to host world mega } \\
\text { events. }\end{array}$ & 5.91 & 1.04 \\
\hline ESDI 5 & $\begin{array}{l}\text { In my view, the Putrajaya Flower \& Garden Festival } \\
\text { was successfully hosted in Putrajaya. }\end{array}$ & 5.99 & 1.00 \\
\hline ESDI 6 & I will visit Putrajaya again. & 6.22 & 0.94 \\
\hline
\end{tabular}


The final descriptive analysis was done on the event sustainability and destination image to evaluate on how local community see the contribution of one or more events as a co-operative branding activity to strengthen the destination image of a place. Most of the respondents agreed that the festival effectively addressed a major theme of Putrajaya as a city-in-garden with a mean score of $(M=5.86)$ and a standard deviation of $(S D=.92)$. From that result, it was apparent that the festival had achieved its goal $(M=5.85)$ with a standard deviation of $(S D=1.01)$. Venue of an event also played one of important roles to promote an event as respondents agreed that Putrajaya had enhanced the visibility of FLORIA Putrajaya for visit with a mean score of $(M=5.86)$ and a standard deviation of $(S D=1.05)$. Since FLORIA Putrajaya has been announced as an international event, respondents mostly agreed that Putrajaya has the capability to host world mega events $(M=5.91)$ with a standard deviation of $(S D=1.04)$. With mean score of $(M=5.99)$ and standard deviation $(S D=1.00)$, it was shown that in the view of respondents, the FLORIA Putrajaya has been successfully hosted in Putrajaya. Also, most of respondents strongly agreed to visit Putrajaya again $(M=6.22)$ with a standard deviation of $(S D=0.94)$.

\subsection{Spearman's Correlations Analysis}

Table 4: Spearman's Correlations Matrix for study analysis

\begin{tabular}{cccc}
\hline \hline & & CS & ESDI \\
\hline LOCAL COMMUNITY & Spearman's Correlation & 1 & $.698^{* *}$ \\
SUPPORT (CS) & Sig. (2-tailed) & & .00 \\
\hline EVENT & $\mathrm{N}$ & 300 & 300 \\
\hline SUSTAINABILITY \& & Spearman's Correlation & $.698^{* *}$ & 1 \\
DESTINATION IMAGE & Sig. (2-tailed) & .00 & .00 \\
(ESDI) & $\mathrm{N}$ & 300 & 300 \\
\hline \hline
\end{tabular}

**Correlation is significant at the 0.01 level (2-tailed).

All SD indicators were seen above 0.7, as seen in tables 2 and 3. Meanwhile, the constructs' composite reliabilities were over 0.9 and between 0.91 and 1.26. Additionally, the derived average variance was also greater than 0.5 threshold with a product of .698 as seen in Table 4 . The measures in this research thus met the convergent validity criteria for the scales as the findings demonstrated that the average square root variances extracted were high (Fornell \& Larcker, 1981). Therefore, in this analysis, the construction validity of scales was acceptable.

\section{Conclusion}

This research has empirically tested the structural connection among determinants that can lead to the effective image of the destination in hosting a particular event. The results showed that local residents' support is an important element in strengthening the sustainability of an event and enhance image of a destination. In detail, the behaviour of local people, local community support and hospitality services in host-destination, assistance from volunteers of the events, as well as educational and guidance signage have all rendered important contributions to the sustainability of the event as well as image of the destination. This study further reflects many previous findings concerning the impact of support from local population on the sustainability of an event and its quality (Gursoy \& Kendall, 2006; Misener \& Mason, 2006; Fredline \& Faulker, 2000). The participants accepted mainly that the residents have fully supported the event besides being friendly. Effective festivals and events draw together residents and tourists to share the special and unique essence of a culture. These events provide various advantages for a community and tourism area including high visitors and expenses, decreased seasonality, frequent trips, as well as enhanced public visibility and word-of-mouth recommendations, among others. From the findings, it can be concluded that it is essential to often consider and monitor the local society effects (economic, social, cultural and environmental) of events. This determinant is particularly daunting for the event venue, provided that the festival would last one week, which ensures that the surrounding population will participate over a significantly longer time than a 
few days. In the situation of this study, it is important for volunteers and local people to be mobilised and educated in assisting visitors to organise successful events. Therefore, relevant suggestions should be addressed, including observations on the potential process of the growth of the event's management as well as interventions from local authorities and the cultural sector. Further research should therefore explore the significance of this relation in numerous industries utilising various goods.

\section{References}

Barron, P., \& Rihova, I. (2011). Motivation to volunteer: a case study of the Edinburgh International Music Festival. International Journal of Event and Festival Management, 2(3), 202-17.

Berkes, F., \& Folke, C. (Eds.). (1998). Linking social and ecological systems: Management practices and social mechanisms for building resilience. Cambridge, UK: The Press Syndicate of the University of Cambridge.

Boo, S., \& Busser, J. A. (2006). Impact analysis of a tourism festival on tourists' destination images. Event Management, 9(4), 223-237.

Bramwell, B., \& Lane, B. (1993). Sustainable tourism: an evolving global approach. Journal of Sustainable Tourism, 1(1), 1-5.

Capra, F. (2002). The hidden connections: A science for sustainable living. New York, NY: Anchor Books.

Eagles, P. F. J., McCool, S. F., \& Haynes, C. F. (2002). Sustainable tourism in protected areas: Guidelines for planning and management. Gland, Switzerland: International Union for the Conservation of Nature.

Fallon, L. D., \& Kriwoken, L. K. (2003). Community involvement in tourism infrastructure: the case of the Strahan Visitor Centre, Tasmania. Tourism Management, 24, 289-308.

Fredline, E. \& Faulkner, B. (2000). Host community reactions: A cluster analysis. Annals of Tourism Research, 27(3), 763-84.

Fornell, C., \& Larcker, D.F. (1981). Evaluating structural equation models with unobservable and measurement error. Journal of Marketing Research, Vol. 18 No. 1, pp. 39-50.

Gursoy, D., \& Rutherford, D. G. (2004). Host attitudes toward tourism e an improved structural model. Annals of Tourism Research, 31(3), 495-516.

Gursoy, D., \& Kendall, K.W. (2006). Hosting mega events: Modeling local support. Annals of Tourism Research, Vol. 33 No. 3, pp. 603-23.

Haxton, P.A. (2000). The perceived role of community participation in the mega-event hosting process: A case study of the Atlanta 1996 and Sydney 2000 Olympic Games. PhD Dissertation, University of Technology, Sydney.

Jago, L., Dwyer, L., Lipman, G., van Lill, D., \& Vorster, S. (2010). Optimising the potential of megaevents: $\quad$ An overview. International Journal of Event and Festival Management, Vol. 1 No. 3, pp. 230-7.

Laing, J., \& Frost, W. (2010). How green was my festival: Exploring challenges and opportunities associated with staging green events. International Journal of Hospitality Management, 29, 261-267. doi.org/10.1016/j.ijhm.2009.10.009

Lee, T. H. (2011). How recreation involvement, place attachment and conservation commitment affect environmentally responsible behavior. Journal of Sustainable Tourism, 19(7), 895-915.

Lepp, A. (2007). Residents' attitudes towards tourism in Bigodi village, Uganda. Tourism Management, 28, 876-885.

Mehmetoglu, M. (2001). Economic scale of community-run festivals: a case study. Event Management, 7(2), 93-102.

Mehmetoglu, M., \& Ellingsen, K. A. (2005). Do small-scale festivals adopt "market orientation" as a management philosophy? Event Management, 9(3), 119-132.

Misener, L., \& Mason, D.S. (2006). Developing local citizenship through sporting events: Balancing community involvement and tourism development. Current Issues in Tourism, Vol. 9 No. 4\&5, pp. 384-98. 
Nicholas, L., Thapa, B., \& Ko, Y. (2009). Residents' perspectives of a world heritage site e the Pitons Management Area, St. Lucia. Annals of Tourism Research, 36(3), 390-412.

Puczkó, L., \& Rátz, T. (2000). Tourist and resident perceptions of the physical impacts of tourism at Lake Balaton, Hungary: issues for sustainable tourism management. Journal of Sustainable Tourism, 8(6), 458-478.

Wang, H., Yang, Z., Chen, L., Yang, J., \& Li, R. (2010). Minority community participation in tourism: a case of Kanas Tuva villages in Xinjiang, China. Tourism Management, 31(6), 759-764.

Roche, M. (1998). Mega-events, culture and modernity: expos and the origins of public culture. International Journal of Cultural Policy, Vol. 5 No. 1, pp.1-31.

Sebele, L. S. (2010). Community-based tourism ventures, benefits and challenges: Khama Rhino Sanctuary Trust, Central District, Botswana. Tourism Management, 31, 136e146.

Sekaran U, \& Bougie, R. (2010). Research methods for business: A skill building approaches (5thed.). Chichester: John Willey \& Sons Ltd, 2010.

Solberg, H.A. (2003). Major sporting events: assessing the value of volunteers' work. Managing Leisure, Vol. 8 No. 1, pp. 17-27.

Teh, L., \& Cabanban, A. S. (2007). Planning for sustainable tourism in southern Pulau Banggi: An assessment of biophysical conditions and their implications for future tourism development. Journal of Environmental Management, 85(4), 999-1008.

Yulan Y. Y., (2013). Adding environmental sustainability to the management of event tourism. International Journal of Culture, Tourism and Hospitality Research, Vol. 7 Iss. 2 pp. 175 $-183$. 